\title{
Isolation and Characterization of Nonylphenol-degrading Bacteria
}

\author{
Dae-Ung Yu ${ }^{1}$, Dong-Myung Kim ${ }^{2}$, Yong-Hyun Chung ${ }^{2}$, Yang-Bong Lee ${ }^{1}$ and Young-Mog Kim ${ }^{1 *}$ \\ ${ }^{1}$ Department of Food Science and Technology, Pukyong National University, Busan 608-737, Korea \\ ${ }^{2}$ Department of Ecological Engineering, Pukyong National University, Busan 608-737, Korea
}

\begin{abstract}
To isolate a nonylphenol (NP)-degrading bacterium, we isolated a single colony from the NP-degrading microbial consortium SW-3, which was previously isolated from an aqueous environment. Ten colonies that exhibited different cell morphologies were isolated and the strains were named SW-3-A, -B, -C, -D, -E, -F1, -F2, -G, -H, and -I. The ability of isolates to degrade NP was evaluated by kinetic analysis by the constant of NP degradation rate $\left(\mathrm{k}_{1}\right)$ and the half-life time of NP degradation ( $\left.\mathrm{t}_{1 / 2}\right)$. SW-3-F1, $-F 2$, -G, and -I strains were superior at degrading NP. The $k_{1}$ and $t_{1 / 2}$ values of the four strains were sixfold higher and one-sixth lower, respectively, than those of the consortium strain. Additionally, SW-3-F1, -G, and -I strains were tested for their ability to degrade NP during coculture. NP degradation by coculture with a combination of all three strains was inferior to that of culture conducted with single isolates, suggesting that the three strains are antagonistic toward each other during NP degradation.
\end{abstract}

Key words: Biodegradation, Endocrine disruptor, Microbial degradation, Nonylphenol

\section{Introduction}

Nonylphenol (NP) is a ubiquitous pollutant, resulting from the biodegradation of widely used NP polyethoxylate surfactants (Corvini et al., 2004). Polyethoxylate is degraded slowly during aerobic and anaerobic degradation to NP in sewage disposal plants and other aqueous environments (Giger et al., 1984; Ahel et al., 1994; Fries and Puttmann, 2003). NP is an endocrine disruptor due to its weak ability to mimic estrogen, disrupting the natural balance of hormones in affected organisms (Gronen et al., 1999). NP is discharged into streams or coastal waters by industrial wastewater or the sewage disposal process. Its role as an endocrine disruptor has been extensively studied in aquatic organisms (Yadetie and Male, 2002; Karels et al., 2003; Hernandez-Raquet et al., 2007). However, few information is available on the distribution of NP worldwide. In Korea, NP was detected in the range of 113 to 3,890 ng per gram dry weight at Masan Bay, Gyeongnam (Khim et al.,
1999), and 6.0 to $119.1 \mu \mathrm{g}$ per $\mathrm{kg}$ from the sediments collected from 11 different rivers (Cho et al., 2004), and $3.6 \mu \mathrm{g}$ per L in Sihwaho Bay, Gyeongido (Li et al., 2004). These reports revealed that NP is extensively distributed in aquatic environments. Since trace levels of NP in the aquatic environment can act as an endocrine disruptor, technologies that degrade environmental NP are greatly needed.

A biological decomposition method by microorganisms, called bioremediation, has been considered an environmentally favorable method to restore environments contaminated with harmful non-resolvable chemicals (Kim et al., 2004; Lee et al., 2009; Song et al., 2011). Bioremediation decomposes organic toxic substances into water and carbon dioxide (Ripp et al., 2000; Kang and Kim, 2007; Kim et al., 2007; Lee et al., 2009). Several reports have indicated successful bioremediation of NP (Tanghe et al., 1999; Fujii et al., 2000, 2001; Corvi-
Open Access http://dx.doi.org/10.5657/FAS.2012.0091

This is an Open Access article distributed under the terms of the Creative Commons Attribution Non-Commercial License (http://creativecommons. org/licenses/by-nc/3.0/) which permits unrestricted non-commercial use, distribution, and reproduction in any medium, provided the original work is properly cited. pISSN: 2234-1749 eISSN: 2234-1757
Received 13 February 2012; Revised 28 February 2012 Accepted 2 March 2012

*Corresponding Author

E-mail: ymkim@pknu.ac.kr 
ni et al., 2004; Junghanns et al., 2005; Shi and Bending, 2007). However, most studies have been performed on soil environments. No reports have been published regarding NP bioremediation in aquatic environments. Therefore, this study isolated NP-degrading bacteria from the microbial consortium SW-3, which was previously isolated from an aqueous environment (Song et al., 2011). We also performed a kinetic analysis of NP degradation by individual and groups of bacterial strains.

\section{Materials and Methods}

\section{Chemicals}

NP (assay $>85 \%$ ) was purchased from Fluka (St. Louis, MO, USA). Other reagents used in the analysis were analytical grade and purchased from a commercial source.

\section{Medium for isolation of NP-degrading bacteria}

Yeast nitrogen base (YNB) without amino acids (Difco, Franklin Lakes, NJ, USA) medium was used as a basal medium for the isolation of NP-degrading bacteria as previously described (Fujii et al., 2000, 2001; Corvini et al., 2004). YNB medium containing 100 ppm NP was used for enrichment cultures and YNB agar plates containing 100 ppm NP were used for isolating NP-degrading bacteria.

\section{Isolation and culture of NP-degrading bacteria}

To isolate NP-degrading bacteria from the NP-degrading microbial consortium SW-3 (Song et al., 2011), the consortium strain was cultivated in YNB medium containing 100 ppm NP at $25^{\circ} \mathrm{C}$ under aerobic conditions. $100 \mathrm{uL}$ of the culture was taken at intervals and spread on YNB agar plates containing $100 \mathrm{ppm} \mathrm{NP}$. The agar plate was incubated at $25^{\circ} \mathrm{C}$ for 7 days. Single colonies grown on the plate were collected for further studies The growth of bacteria in the medium containing 100 ppm NP was measured by a change of optical density at $600 \mathrm{~nm}$.

\section{Identification of NP-degrading bacteria}

Bacterial strains isolated from the NP-degrading microbial consortium were identified by their morphological, biochemical, and genetic characteristics. A light microscope (Motic 300; Motic, Richmond, BC, Canada) and a scanning electron microscope (SEM; model S-2400; Hitachi Ltd., Tokyo, Japan) were used for the morphological analysis. VITEK Gram Negative Identification cards (GNI-) or VITEK Gram Positive Identification cards (GNI+) (Biomerieux Inc., St. Louis, MO, USA) were used for physicochemical analysis. Identification of strains was determined through homology analysis of $16 \mathrm{~S}$ rDNA sequences. Two oligonucleotides (27F: 5'-GTTTG-
GATCCTGGCTCAG-3' and 1492R: 5'-AAGGAGGGGATCCAGCC-3') were used for polymerase chain reaction (PCR) to amplify 16S rDNA (Dunbar et al., 2000). PCR was conducted as follows: $2 \mu \mathrm{L}$ of 20 pmole each primer, $25 \mathrm{ng}$ DNA template, $0.5 \mu \mathrm{L}$ Taq polymerase $(2.5 \mathrm{U}), 5 \mu \mathrm{L}$ of $10 \times$ Taq polymerase buffer, $1 \mu \mathrm{L}$ of $10 \mathrm{mM} d \mathrm{NTP}$, and $39 \mu \mathrm{L}$ of $\mathrm{dH}_{2} \mathrm{O}$ was denatured for $2 \mathrm{~min}$ at $94^{\circ} \mathrm{C}$. After denaturation, reactions cycled 25 times at $94^{\circ} \mathrm{C}$ for $1 \mathrm{~min}, 52^{\circ} \mathrm{C}$ for $1 \mathrm{~min}$, and $72^{\circ} \mathrm{C}$ for $2 \mathrm{~min}$, followed by incubation at $72^{\circ} \mathrm{C}$ for $5 \mathrm{~min}$. The amplified PCR products were sequenced by SolGent (Daejeon, Korea). Homology searches of sequences were conducted using a ribosomal database (http://www.ncbi.nim.nih.gov/ BLAST/).

\section{NP extraction and HPLC analysis}

The ability of a bacterial strain to degrade NP was determined by analysis of NP content remaining in medium by high-performance liquid chromatography (HPLC). After inoculation of $1 \%$ pre-culture, cells were aerobically cultivated at $25^{\circ} \mathrm{C}$. One milliliter of culture was reserved for analysis. Then, $4 \mathrm{~mL}$ of deionized water and $15 \mathrm{~mL}$ of acetonitrile were added. The solution was mixed for $3 \mathrm{~min}$ by a vortex mixer to extract the remaining NP. After extraction, the upper layer was carefully reserved, filtered through a $0.2-\mu \mathrm{m}$ filter (DISMIC25AS; Advantec, Tokyo, Japan), and then analyzed by HPLC (Flexar HPLC System; PerkinElmer, Waltham, MA, USA) equipped with $\mathrm{a}_{18}$ reverse-phase column $(250 \mathrm{~mm} \times 4.6 \mathrm{~mm}$, I.D. $5 \mu \mathrm{m}$; Shiseido Co., Tokyo, Japan). For detection of NP, samples were eluted with $75 \%$ acetonitrile in $25 \%$ water at a flow rate of $1 \mathrm{~mL}$ per minute. Eluates were monitored at 277 $\mathrm{nm}$. Remaining NP was indicated as a percentage value of the total reduced NP peak.

\section{Kinetic analysis of NP degradation}

Kinetic analysis of NP degradation under various conditions was estimated according to a first-order model described by the following formula:

$$
\begin{aligned}
& \mathrm{k}_{1}=-\left\{\left(\ln \mathrm{S} / \mathrm{S}_{0}\right) / \mathrm{t}\right\}, \\
& \mathrm{t}_{1 / 2}=\ln 2 / \mathrm{k}_{1},
\end{aligned}
$$

where $\mathrm{S}_{0}$ is initial the NP concentration, $\mathrm{S}$ is the residual NP concentration at sampling time $t, \mathrm{k}_{1}$ is the NP degradation rate constant (1/day), and $t_{1 / 2}$ is the half-life of NP degradation (days). A significant difference was tested by ANOVA (Chang et al., 2007).

\section{Results and Discussion}

Isolation of NP-degrading bacteria from the microbial consortium SW-3 
To obtain bacterial strains that utilized NP as a carbon source, the NP-degrading microbial consortium SW-3 strain was cultivated and then spread on an agar plate as described in the Materials and Methods. Colonies grown on YNB agar plates containing $100 \mathrm{ppm}$ NP were reserved for further study. Morphology of each colony was confirmed by Gram staining under a light microscope. Ten colonies that exhibited different cell morphologies were obtained by single colony isolation. Strains were named SW-3-A, -B, -C, -D, -E, -F1, -F2, -G, -H, and $-\mathrm{I}$. All strains isolated from the microbial consortium were Gram (-) bacteria except SW-3-F2 (data not shown).

\section{Kinetic analysis of NP degradation by NP-degrad- ing bacteria}

Growth of the isolated bacteria was observed in YNB medium containing $100 \mathrm{ppm} \mathrm{NP}$, suggesting that the isolates are capable of using NP as a carbon source (data not shown). As bacterial growth progressed, NP concentrations decreased. For each isolate tested, NP was not detected after 40 days (data not shown). A previous report showed that the Sphingomonas xenophaga Bayram strain was capable of degrading over $90 \%$ of NP after 2 weeks of incubation (Gabriel et al., 2005) and that the Sphingomonas sp. TTNP3 strain degraded over $80 \%$ of NP within 2 weeks (Corvini et al., 2004). Additionally, a microbial consortium isolated from an aqueous environment exhibited NP-degrading activity that metabolized $70 \%$ of NP after 45 days incubation (Fujii et al., 2000). Due to the complete remediation of NP by the isolated bacterial strains of the present study, we hypothesized that these strains would

Table 1. Kinetic analysis of nonylphenol degradation by bacteria isolated from nonylphenol-degrading consortium SW-3

\begin{tabular}{lccc}
\hline Strain & $\begin{array}{c}\mathbf{k}_{1} \\
(\mathbf{1} / \mathbf{d a y})\end{array}$ & $\begin{array}{c}\mathbf{t}_{\mathbf{1} / 2} \\
\text { (day) }\end{array}$ & $\begin{array}{c}\boldsymbol{r}^{2} \\
\text { (correlation coefficient) }\end{array}$ \\
\hline Control & 0.011 & 61.8 & 0.99 \\
SW-3 & 0.074 & 9.3 & 0.99 \\
SW-3-A & 0.092 & 7.5 & 0.99 \\
SW-3-B & 0.102 & 6.8 & 0.98 \\
SW-3-C & 0.100 & 6.9 & 0.99 \\
SW-3-D & 0.103 & 6.7 & 0.99 \\
SW-3-E & 0.159 & 4.4 & 0.99 \\
SW-3-F1 & 0.340 & 1.7 & 0.99 \\
SW-3-F2 & 0.456 & 1.5 & 0.99 \\
SW-3-G & 0.399 & 1.7 & 0.99 \\
SW-3-H & 0.054 & 12.8 & 0.99 \\
SW-3-I & 0.399 & 1.7 & 0.99 \\
\hline
\end{tabular}

Nonylphenol (NP) was extracted from yeast nitrogen base medium containing 100 ppm NP as described in Materials and Methods. Control means non-inoculated samples. represent an environmentally favorable technology to restore environments contaminated with NP.

To evaluate NP-degrading activities between the isolates in more detail, a kinetic analysis was performed as described in the Materials and Methods. Based on the analysis of $\mathrm{k}_{1}$ and $\mathrm{t}_{1 / 2}$ values, all strains except SW-3-H exhibited higher NP-degrading activity as compared to the consortium strain (Table 1). SW-3-F1, -F2 -G, and -I strains exhibited superior NPdegrading ability compared to other isolates and the consortium strain. The $\mathrm{k}_{1}$ values of SW-3-F1, -F2, -G, and -I strains ranged from 0.340 to 0.456 and were sixfold higher than that of the consortium strain. The $t_{1 / 2}$ values by the four strains dramatically decreased in the range of 1.5 to 1.7 days. The values were one-sixth that of the consortium strain (Table 1). A previous kinetic analysis of NP degradation in soil reported a $\mathrm{k}_{1}$ value of 0.054 and $\mathrm{t}_{1 / 2}$ value of 12.8 at $\mathrm{pH} 7.0$ and $20^{\circ} \mathrm{C}$ (Chang et al., 2007). These results suggest that isolates SW3-F1, -F2, -G, and -I will facilitate the production of a starter strain for the biodegradation of NP.

\section{Identification of NP-degrading bacteria isolated from the microbial consortium SW-3 strain}

Four strains (SW-3-F1, -F2, -G, and -I) that exhibited superior NP-degrading activities were selected for further study. To investigate the cell surface structure of each isolate, morphological features of SW-3-F1, -F2, -G, and -I were identified by SEM analysis. As shown in Fig. 1, SW-3-F1, -G, and -I were bacilli and SW-3-F3 was a coccus. SW-3-F1, -G, and -I were identified as Gram (-) bacilli and SW-3-F2 was a Gram (+) coccus. The biological characteristics of NP-degrading bacteria are listed in Table 2. The SW-3-F1 and -G strains exhibited similar biological characteristics, suggesting that these strains were related (Table 2). The others showed different biological characteristics.

The analysis of biological characteristics suggested that SW-3-F1 and SW-3-G were related. However, these biological characteristics provided limited information regarding the identification of bacteria. Therefore, we performed a genetic analysis using bacterial $16 \mathrm{~S}$ rDNA. PCR products of $16 \mathrm{~S}$ rDNA about 1.3 to $1.5 \mathrm{~kb}$ were obtained (data not shown). $16 \mathrm{~S}$ rDNA sequences were matched against $16 \mathrm{~S}$ rDNA sequences in GenBank using BLAST. SW-3-F1, -F2, -G, and -I exhibited 99\% identity with Ochrobactrum sp., Staphylococcus sp., Achromobacter sp., and Alcaligenes sp., respectively (Table 3). Ochrobactrum sp. is a dominant NP-degrading bacterium in soil (Chang et al., 2007). Community analysis of a NP-degrading bacterial consortium obtained from a textile wastewater pretreatment plant revealed Achromobacter sp. (Di Gioia et al., 2008). This is the first study showing that Staphylococcus sp. can degrade NP. However, Sphingomonas has been reported to bioremediate 4-NP, but was not isolated in this study (Thanghe et al., 1999; Fujii et al., 2001; Corvini et al., 2004; Gabriel et al., 2005). 


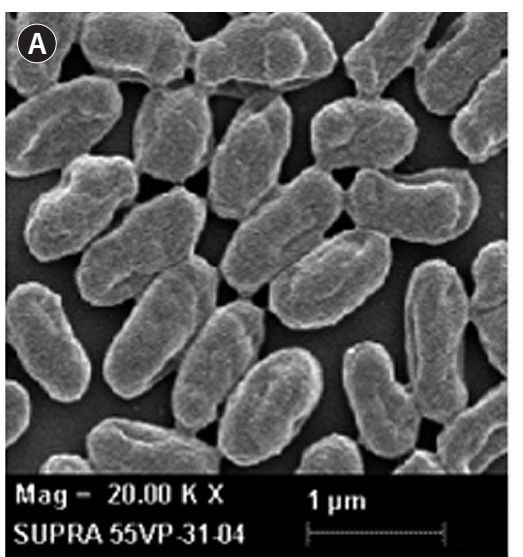

SW-3-F1

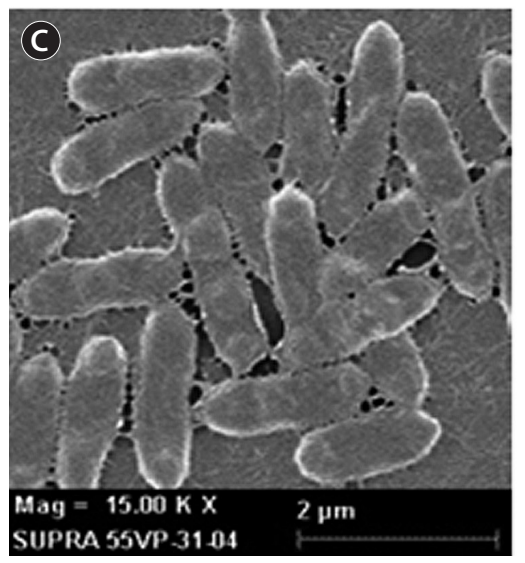

SW-3-G

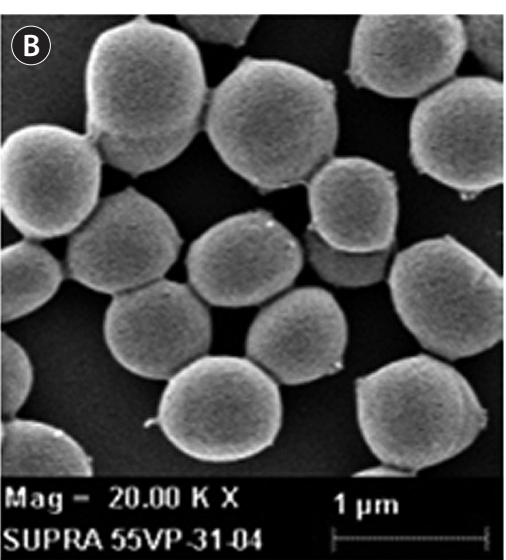

SW-3-F2

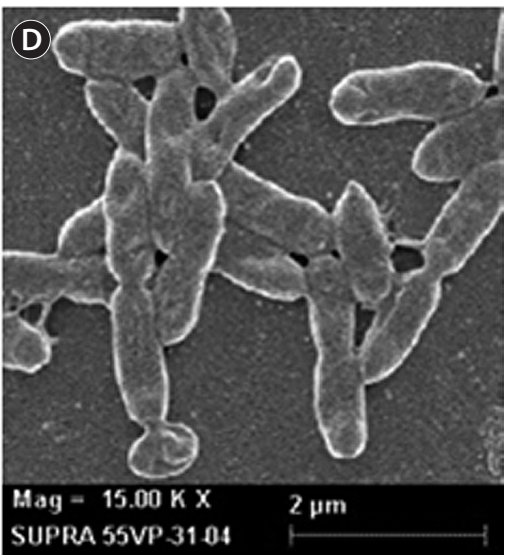

SW-3-I

Fig. 1. Scanning electron micrograph of nonylphenol-degrading bacteria isolated from the microbial consortium SW-3. Scale bars represents: $A, B=1 \mu \mathrm{m} ; C, D=2 \mu \mathrm{m}$.

\section{NP degradation by coculture of isolates}

Kinetic analysis of NP-degrading bacteria revealed that four strains (SW-3-F1, -F2, -G, and -I) were capable of efficiently degrading NP. However, SW-3-F2 exhibited high homology with Staphylococcus saprophyticus, a pathogen often implicated in urinary tract infections (Kuroda et al., 2005). Therefore, the SW-3-F1, -G, and -I strains were chosen to investigate the coculture effects on NP degradation. All three strains were mixed in the following variations: SW-3-F1/G, SW-3-F1/-I, SW-3-G/-I, and SW-3-F1/-G/-I. As bacterial growth progressed, the concentration of NP gradually decreased over 40 days of cultivation. In the case of SW-3-G/-I, SW-3-F1/-G, and SW-3-F1/-G/-I, NP was degraded over $85 \%$ within 15 days of incubation (data not shown). By coculture of SW-3-F1/-I, over $85 \%$ NP was degraded within 20 days (data not shown). However, NP was still detected in all cocultures after 40 days of incubation. As shown in the above results, the NP-degrading pattern by the coculture of isolates was different according which isolates were mixed together. To evaluate
NP-degrading activities between cocultures, a kinetic analysis was conducted as described in the Materials and Methods. The $\mathrm{k}_{1}$ values by cocultures of isolates (SW-3-G/-I, SW-3-F1/-G, SW-3-F1/-I, and SW-3-F1/-G/-I) ranged from 0.081 to 0.092 . This was 1.3-fold higher than the consortium SW-3 strain. The $\mathrm{t}_{1 / 2}$ values steadily decreased to between 7.5 and 8.6 days lower than those of the consortium strain (Table 4). Thus, the efficacy of NP degradation by coculture performed with a combination of three strains was inferior to that of culture with a single isolate. This result suggested that the three strains (SW3-F1, -G and -I) antagonize NP degradation during coculture (Tables 3 and 4).

NP was not detected in a three-membered (BCaL1, BCaL2, and VA 160 strains) coculture experiment after 25 days of culture (Di Gioia et al., 2004). Indeed, NP degradation was enhanced in $\mathrm{BCaL} 1 / \mathrm{BCaL} 2$ cultures by coculturing them with the non-degrading Bacillus VA 160 strain. We hypothesize that NP-degrading bacteria isolated in the current study are not suitable to degrade NP under coculture conditions. 
Yu et al. (2012) Isolation and Characterization of Nonylphenol-degrading Bacteria

Table 2. Biochemical characteristics of SW-3-F1,-F2, -G and I strains isolated from the nonylphenol-degrading microbial consortium SW-3

\begin{tabular}{|c|c|c|c|c|c|}
\hline \multirow{2}{*}{ Mnemonic } & \multirow{2}{*}{ Biochemical test } & \multicolumn{4}{|c|}{ Strain } \\
\hline & & SW-3-F1 & SW-3-F2 & SW-3-G & SW-3-I \\
\hline APPA & $\alpha$-Phe-proarylamidase & - & - & - & - \\
\hline $\mathrm{ADO}$ & Adonitol & + & - & + & + \\
\hline PyrA & L-Pyrrolydonyl-arylamidase & + & $(-)$ & - & - \\
\hline IARL & L-Arabitol & + & - & + & + \\
\hline dCEL & D-Cellobiose & + & - & + & + \\
\hline BGAL & $\beta$-Galactopyranosidase & - & + & - & - \\
\hline $\mathrm{H}_{2} \mathrm{~S}$ & $\mathrm{H}_{2}$ Sprodustion & - & - & - & - \\
\hline BNAG & $\beta$-N-Acetylglucosaminidase & - & - & - & - \\
\hline AGLTp & Glutamyl-arylamidasepNA & - & - & - & - \\
\hline dGLU & D-glucose & + & + & + & + \\
\hline GGT & $\gamma$-Glutamyltransferase & - & - & - & - \\
\hline OFF & Fermentativeglucose & - & - & - & - \\
\hline BGLU & $\beta$-Glucosidase & - & - & - & - \\
\hline dMAL & D-Maltose & + & + & + & + \\
\hline dMAN & D-Mannitol & + & + & + & + \\
\hline dMNE & D-Mannose & + & - & - & - \\
\hline BXYL & $\beta$-Xylosidase & - & - & - & - \\
\hline BAlap & $\beta$-Alaninearylamidase & - & - & - & - \\
\hline ProA & L-ProlinearylamidasepNA & + & - & - & - \\
\hline LIP & Lipase & - & - & - & + \\
\hline PLE & Palatinose & + & - & + & + \\
\hline TyrA & Tyrosinearylamidase & - & - & - & - \\
\hline URE & Urease & - & + & - & - \\
\hline dSOR & D-Sorbitol & + & - & + & + \\
\hline SAC & Sucrose & + & + & + & + \\
\hline dTAG & D-Tagatose & + & - & + & + \\
\hline dTRE & D-Trehalose & + & + & + & + \\
\hline CIT & Citrate(sodium) & - & - & - & - \\
\hline MNT & Malonate & - & - & - & - \\
\hline $5 \mathrm{KG}$ & 5-Keto-D-gluconate & - & - & - & - \\
\hline ILATk & L-Lactatealkalinisation & - & + & - & - \\
\hline AGLU & $\alpha$-Glucosidase & - & - & - & - \\
\hline SUCT & Succinatealkalinisation & - & - & - & - \\
\hline NAGA & $\beta$-N-acetyl-galactosaminidase & - & - & - & - \\
\hline AGAL & $\alpha$-Galactosidase & - & - & - & - \\
\hline PHOS & Phosphatase & - & - & - & - \\
\hline GlyA & Glycine-arylamidase & + & - & - & - \\
\hline ODC & Omithinedecarboxylase & - & - & - & - \\
\hline LDC & Lysinedecarboxylase & - & - & - & - \\
\hline IHISa & L-Histidineassimilation & - & - & - & - \\
\hline CMT & Courmarate & - & + & - & - \\
\hline BGUR & $\beta$-Glucuronidase & - & - & - & - \\
\hline O129R & $\mathrm{O} / 129$ Resistance & - & - & - & - \\
\hline GGAA & Glu-gly-arg-arylamidase & - & - & - & - \\
\hline IMLTa & L-Malateassimilation & - & - & - & - \\
\hline ELLM & Ellman & + & - & - & - \\
\hline ILATa & L-Lactateassimilation & - & - & - & - \\
\hline
\end{tabular}


Fish Aquat Sci 15(2), 91-97, 2012

Table 3. Identification of SW-3-F1, SW-3-F1,-F2, - G and -I strains based on the homology search of $16 \mathrm{~S}$ rDNA sequence

\begin{tabular}{|c|c|c|}
\hline Strain & Reference (accession no.) & Identity $(\%)$ \\
\hline \multirow[t]{4}{*}{ SW-3-F1 } & Ochrobactrum anthropi CCUG 1821(AM114404) & 99.0 \\
\hline & Ochrobactrum sp. CA01 (HQ670703) & 99.0 \\
\hline & Ochrobactrum sp. 1sd01 (GQ180164) & 99.0 \\
\hline & Ochrobactrum tritici SCII24 (AM114402) & 99.0 \\
\hline \multirow[t]{4}{*}{ SW-3-F2 } & Staphylococcus sp. BQN4T-04 (FJ380997) & 99.0 \\
\hline & Staphylococcus sp. 2qH-9 (EU489561) & 99.0 \\
\hline & Staphylococcus saprophyticus subsp. saprophyticus BQN1T-01d (FJ380970) & 99.0 \\
\hline & Staphylococcus saprophyticus subsp. saprophyticus BAC2101 (HM355690) & 99.0 \\
\hline \multirow[t]{4}{*}{ SW-3-G } & Achromobacter sp. DG (HQ437668) & 99.0 \\
\hline & Achromobacter sp. P3 (FJ556879) & 99.0 \\
\hline & Achromobacter insolitus CCM7182 (FM999733) & 99.0 \\
\hline & Alcaligenaceae bacterium a001-61 (HM468067) & 99.0 \\
\hline \multirow[t]{4}{*}{ SW-3-I } & Alcaligenes sp. MH112 (FJ626643) & 99.0 \\
\hline & Achromobacter sp. P3 (FJ556879) & 99.0 \\
\hline & Alcaligenes sp. cxh-4 (EF059708) & 99.0 \\
\hline & Achromobacter insolitus CCM7182 (FM999733) & 99.0 \\
\hline
\end{tabular}

Table 4. Kinetic analysis of nonylphenol degradation by the coculture

\begin{tabular}{lccc}
\hline Strains & $\begin{array}{c}\mathbf{k}_{1} \\
\text { (1/day) }\end{array}$ & $\begin{array}{c}\mathbf{t}_{\mathbf{1} / \mathbf{2}} \\
\text { (day) }\end{array}$ & $\begin{array}{c}\boldsymbol{r}^{\mathbf{2}} \\
\text { (correlation coefficient) }\end{array}$ \\
\hline Control & 0.011 & 61.8 & 0.99 \\
SW-3 & 0.074 & 9.3 & 0.99 \\
SW-3-G/-I & 0.081 & 8.6 & 0.99 \\
SW-3-F1/-I & 0.092 & 7.5 & 0.99 \\
SW-3-F1/-G & 0.086 & 8.0 & 0.99 \\
SW-3-F1/-G/-I & 0.086 & 8.0 & 0.99 \\
\hline
\end{tabular}

Nonylphenol (NP) was extracted from YNB medium containing $100 \mathrm{ppm}$ NP as described in Materials and Methods. Control means non-inoculated samples.

\section{Acknowledgments}

This work was supported by the research fund of the Busan Environmental Technology Center (11-2-30-33).

\section{References}

Ahel M, Giger W and Koch M. 1994. Behaviour of alkylphenol polyethoxylate surfactants in the aquatic environment-I. Occurrence and transformation in sewage treatment. Water Res 28, 1131-1142.

Chang BV, Chiang BW and Yuan SY. 2007. Biodegradation of nonylphenol in soil. Chemosphere 66, 1857-1862.

Cho HS, Kim YO, Seol SW and Horiguchi T. 2004. A study on the pol- lution of nonylphenol in surface sediment in Gwangyang bay and Yeosu sound. J Environ Sci 13, 561-570.

Corvini PFX, Meesters RJW, Schäffer A, Schröder HF, Vinken R and Hollender J. 2004. Degradation of a nonylphenol single isomer by Sphingomonas sp. strain TTNP3 leads to a hydroxylation-induced migration product. Appl Environ Microbiol 70, 6897-6900.

Di Gioia D, Fambrini L, Coppini E, Fava F and Barberio C. 2004. Aggregation-based cooperation during bacterial aerobic degradation of polyethoxylated nonylphenols. Res Microbiol 155, 761-769.

Di Gioia D, Salvadori L, Zanaroli G, Coppini E, Fava F and Barberio C. 2008. Characterization of 4-nonylphenol-degradingbacterial consortium obtained from a textile wastewater pretreatment plant. Arch Microbiol 190, 673-683.

Dunbar J, Ticknor LO and Kuske CR. 2000. Assessment of microbial diversity in four southwestern United States soils by 16S rRNA gene terminal restriction fragment analysis. Appl Environ Microbiol 66, 2943-2950.

Fries E and Puttmann W. 2003. Occurrence and behaviour of 4-nonylphenol in river water of Germany. J Environ Monit 5, 598-603.

Fujii K, Urano N, Kimura S, Nomura Y and Karube I. 2000. Microbial degradation of nonylphenol in some aquatic enviroments. Fish Sci 66, 44-48.

Fujii K, Urano N, Ushio H, Satomi M and Kimura S. 2001. Sphingomonas cloacae sp. nov., a nonylphenol-degrading bacterium isolated from wastewater of a sewage-treatment plant in Tokyo. Int J Syst Evol Microbiol 51, 603-610.

Gabriel FLP, Giger W, Guenther K and Kohler HPE. 2005. Differential degradation of nonylphenol isomers by Sphingomonas xenophaga Bayram. Appl Environ Microbiol 71, 1123-1129. 
Giger W, Brunner PH and Schaffner C. 1984. 4-nonylphenol in sewage sludge: accumulation of toxic metabolites from nonionic surfactants. Science 225, 623-625.

Gronen S, Denslow N, Manning S, Barnes S, Barnes D and Brouwer M. 1999. Serum vitellogenin levels and reproductive impairment of male Japanese Medaka (Oryzias latipes) exposed to 4-tertoctylphenol. Environ Health Perspect 107, 385-390.

Hernandez-Raquet G, Soef A, Delgenès N and Balaguer P. 2007. Removal of the endocrine disrupter nonylphenol and its estrogenic activity in sludge treatment processes. Water Res 41, 2643-2651.

Junghanns C, Moeder M, Krauss G, Martin C and Schlosser D. 2005. Degradation of the xenoestrogen nonylphenol by aquatic fungi and their laccases. Microbiology 151, 45-57.

Kang MS and Kim YM. 2007. Characterization of chloroanilines-degrading bacteria isolated from seaside sediment. J Korean Fish Sic 40, 282-287.

Karels AA, Manning S, Brouwer TH and Brouwer M. 2003. Reproductive effects of estrogenic and antiestrogenic chemicals on sheepshead minnows (Cyprinodon variegatus). Environ Toxicol Chem 22, 855-865.

Khim JS, Kannan K, Villeneuve DL, Koh CH and Giesy JP. 1999. Characterization and distribution of trace organic contaminants in sediment from Masan bay, Korea: 1. Instrumental analysis. Environ Sci Technol 33, 4199-4205.

Kim YM, Park K, Joo GJ, Jeong EM, Kim JE and Rhee IK. 2004. Glutathione-dependent biotransformation of the fungicide chlorothalonil. J Agric Food Chem 52, 4192-4196.

Kim YM, Park K, Kim WC, Shin JH, Kim JE, Park HD and Rhee IK. 2007. Cloning and characterization of a catechol-degrading gene cluster from 3,4-dichloroaniline degrading bacterium Pseudomo- nas sp. KB35B. J Agric Food Chem 55, 4722-4727.

Kuroda M, Yamashita A, Hirakawa H, Kumano M, Morikawa K, Higashide M, Maruyama A, Inose Y, Matoba K, Toh H, Kuhara S, Hattori M and Ohta T. 2005. Whole genome sequence of Staphylococcus saprophyticus reveals the pathogenesis of uncomplicated urinary tract infection. Proc Natl Acad Sci USA 102, 13272-13277.

Lee YK, Eom SH, Hwang HJ, Lim KS, Yang JY, Chung YH, Kim DM, Lee MS, Rhee IK and Kim YM. 2009. Cloning and mutational analysis of catechol 2,3-dioxygenase from 3,4-dichloroaniline degrading bacterium Pseudomonas sp. KB35B. J Korean Soc Appl Biol Chem 52, 258-263.

Li D, Kim M, Oh JR and Park J. 2004. Distribution characteristics of nonylphenols in the artificial lake Shihwa, and surrounding creeks in Korea. Chemosphere 56, 783-790.

Ripp S, Nivens DE, Ahn Y, Werner C, Jarrell J, Easter JP, Cox CD, Burlage RS and Sayler GS. 2000. Controlled field release of a bioluminescent genetically engineered microorganism for bioremediation process monitoring and control. Environ Sci Technol 34, 846-853.

Shi S and Bending GD. 2007. Changes to the structure of Sphingomonas spp. communities associated with biodegradation of the herbicide isoproturon in soil. FEMS Microbiol Lett 269, 110-116.

Song WS, Lim KS, Yu DU, Park ME, Jeong ET, Kim DM, Chung YH and Kim YM. 2011. Isolation of a nonylphenol-degrading microbial consortium. Korean J Fish Aquat Sci 44, 325-331.

Tanghe T, Dhooge W and Verstraete W. 1999. Isolation of a bacterial strain able to degrade branched nonylphenol. Appl Environ Microbiol 65, 746-751.

Yadetie F and Male R. 2002. Effects of 4-nonylphenol on gene expression of pituitary hormones in juvenile Atlantic salmon (Salmo salar). Aquat Toxicol 58, 113-129. 